\title{
New tsunami damage functions developed in the framework of SCHEMA project: application to European-Mediterranean coasts
}

\author{
N. Valencia ${ }^{1}$, A. Gardi ${ }^{1, *}$, A. Gauraz ${ }^{2}$, F. Leone ${ }^{2}$, and R. Guillande ${ }^{1}$ \\ ${ }^{1}$ Geosciences Consultants, Paris, France \\ ${ }^{2}$ Laboratoire GESTER \& Département de Géographie, Université Montpellier, France \\ *now at: Aon Benfield, Paris, France
}

Received: 17 September 2010 - Revised: 26 August 2011 - Accepted: 6 September 2011 - Published: 25 October 2011

\begin{abstract}
In the framework of the European SCenarios for tsunami Hazard-induced Emergencies MAnagement (SCHEMA) project (www.schemaproject.org), we empirically developed new tsunami damage functions to be used for quantifying the potential tsunami damage to buildings along European-Mediterranean coasts.

Since no sufficient post-tsunami observations exist in the Mediterranean areas, we based our work on data collected by several authors in Banda Aceh (Indonesia) after the 2004 Indian Ocean tsunami. Obviously, special attention has been paid in focusing on Indonesian buildings which present similarities (in structure, construction material, number of storeys) with the building typologies typical of the EuropeanMediterranean areas.

An important part of the work consisted in analyzing, merging, and interpolating the post-disaster observations published by three independent teams in order to obtain the spatial distribution of flow depths necessary to link the flowdepth hazard parameter to the damage level observed on buildings. Then we developed fragility curves (showing the cumulative probability to have, for each flow depth, a damage level equal-to or greater-than a given threshold) and damage curves (giving the expected damage level) for different classes of buildings. It appears that damage curves based on the weighted mean damage level and the maximum flow depth are the most appropriate for producing, under GIS, expected damage maps for different tsunami scenarios.
\end{abstract}

\section{Introduction}

Tsunami vulnerability assessment is a developing field. Numerous works have been published on the vulnerability of buildings, especially after the 2004 Indian Ocean tsunami.

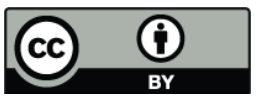

Correspondence to: N. Valencia (nathalia.valencia@laposte.net)
There are several approaches to assess tsunami risk at the regional scale and to evaluate damage suffered by buildings. One of the very first approaches for tsunami risk assessment was developed by Papadopoulos and Dermentzopoulos (1998) for application in northern Crete (Greece): this study was the base for other qualitative and semi-quantitative approaches. The one proposed by Dall'Osso et al. (2006) and Papathoma et al. (2003) is based on the computation of a vulnerability index. In this approach, vulnerability is completely detached from the notion of hazard, thus independent from the flow height values or any other physical value describing the impact of the tsunami. The indexes are computed starting from very different factors (structural features, environment, building use) and given subjective weights to each one of them. Looking at the resulting vulnerability maps, it is not possible to discriminate and quantify the influence of each factor. In the SCHEMA FP6 EC co-funded project (SCenarios for tsunami Hazard-induced Emergencies MAnagement), it was thus decided not to use an index based approach.

Other existing approaches for the estimation of building damage consist in deriving damage functions starting from field observations (Ruangrassamee et al., 2006; Reese et al., 2007; Peiris, 2006) or from field observation combined with photo-interpretation (e.g. Koshimura, 2007; Koshimura et al., 2009a). In general, damage functions found in the literature are developed for only a single typology of buildings. For example:

- Leone et al. $(2006,2010)$ presented damage functions for buildings classified as "B" (brick not-reinforced individual buildings), based on field survey and high resolution imagery for Banda Aceh (Indonesia). They also proposed a qualitative scale for the differentiation of the damage level supported by the buildings (from " $D 0$ : no damage" to " $D 5$ : collapse").

- Peiris (2006) developed vulnerability functions for unreinforced masonry residential properties using the data available for the coastal areas of Sri Lanka. A

Published by Copernicus Publications on behalf of the European Geosciences Union. 
qualitative damage scale is also proposed based on the structural and geotechnical failure. Their "vulnerability function" is a Lognormal cumulative distribution of tsunami submerged height as the demand parameter.

- Finally, Koshimura et al. (2009a) developed fragility functions based on a numerical model of the tsunami and a visual inspection of buildings using high resolution imagery in Banda Aceh, Indonesia. They subdivided a stock of 40000 units into two groups, "survived" and "destroyed". However, no damage scale is given to discriminate the damage level incurred by the analysed buildings. Moreover, no differentiation has been performed by the authors according to the building typologies.

Most of the existing works on damage functions rely on flow depth, which is the only parameter that can be directly measured in the field after a disaster. However, several authors emphasize that besides damages due to hydrostatic forces and hydrodynamic pressures which depend on the flow depth parameter, there are other factors which generate damages to buildings like scour, buoyancy force, drag force, and impact due to debris flow (e.g. Saatcioglu et al., 2006; Reese et al., 2007).

The ICG/NEAMTWS (Intergovernmental Coordination Group for the Tsunami Early Warning and Mitigation System in the North Eastern Atlantic, the Mediterranean and Connected Seas) of the IOC/UNESCO, since its establishment in 2005 , has highlighted the necessity of standardizing the methodology needed for the pre-determination of tsunami damage zones by combining experience from past cases, numerical modelling, and flow results with socio-economic parameters, and to identify strategic stakes through groundbased, airborne-based, or space-based techniques.

In this framework, the co-funded European SCHEMA project (FP6 programme) aimed at contributing to this field by supporting the development of a general methodology, using Earth Observation data, for the production of maps of expected damages associated with different tsunami scenarios.

In this paper, we present the work we carried out within the SCHEMA project in order to develop and apply new damage functions for assessing tsunami damages to buildings.

\section{Methodology}

We started from the database of post-disaster observations collected by Leone et al. $(2006,2010)$ in Banda Aceh (Indonesia) after the December 2004 tsunami. Four main steps were followed in order to obtain new damage functions and to apply them to specific building typologies in EuropeanMediterranean coasts:

- Buildings database
In the first stage of this work, it was necessary to extend the initial observed-buildings database using high resolution satellite and aerial images taken before the event.

\section{- Tsunami hydrodynamic loads}

The tsunami hydrodynamic loads causing damage to buildings are a function of the water flow depth. In this study, the damage is thus linked with the flow depth, which represents the tsunami hazard parameter. Contrary to other authors (e.g. Koshimura et al., 2009a), we did not perform a numerical simulation of the tsunami. We only based our study on observed flow depths after the 2004 tsunami. The water level observations collected by several authors have been analysed and merged into a unique database. Then an interpolation was computed in order to obtain the spatial distribution of flow depths in Banda Aceh.

\section{- Damage functions}

A statistical and probabilistic analysis was performed in order to derive new damage functions for different building typologies. Two kinds of functions were developed: fragility curves, which express the conditional probability of reaching or exceeding a particular damage state " $D$ " for each value of the flow depth $h$, and damage curves, which link the mean damage level to the value of flow depth. Our supposition here is that the flow depth is the demand parameter that governs the hydrodynamic forces that cause damage to buildings.

\section{- Damage assessment and mapping}

A photo-interpretation process was done in order to assign a vulnerability class to the building inventory in the five test sites of the SCHEMA project (Setubal, Portugal; Mandelieu, France; Catania, Italy; Balchik, Bulgaria; Rabat, Morocco). The developed damage functions were finally integrated in a geographic information system (GIS) in order to be used for the production of maps of expected damages in the European-Mediterranean coasts.

\section{Buildings data base}

\subsection{Initial Database}

Leone et al. (2006, 2010) built up a building inventory in Banda Aceh area in order to classify constructions according to both the type of structure and to the level of damage due to the tsunami forces. This database was built up based on a field survey and a visual interpretation of high resolution imageries of the affected area: a Quick Bird satellite view taken on 2004-06-23 (60-cm resolution), aerial photographs from January and June 2005 (30-cm resolution), a Quick Bird satellite imagery from 2004-12-28 (60-cm resolution), and a Ikonos satellite imagery from 2005-03-01 (1-m resolution). The field survey was carried out from 16 to 25 January 2006, mainly focusing on partially damaged buildings. 
Due to the magnitude and scale of the disaster in Banda Aceh area, damages were still well visible one year after the disaster despite some rehabilitation to buildings and some new constructions. In addition, as mentioned before, the field survey was supported by high resolution imageries dating from before and two days after the disaster, when clean up process had not yet started. As also highlighted by Koshimura et al. (2009a), very high resolution imagery expands the possibilities of detecting the extent of tsunami affected areas and damage to structures, helping in completing the databases gathered during post-tsunami surveys, which are hardly satisfactory because of limitations in time as well as in economic and human resources.

Buildings of Banda Aceh have been classified by Leone et al. (2010) into five categories according to their structure type: from class "A" (the most vulnerable, made of wood, single storey) to class "E" (the most resistant, well designed, made of reinforced concrete with columns and infill walls). The construction material, number of storeys, geometry, and dimension are the elements on which this classification is based. In general, each different class is also characterized by a different roof type, which helps in recognizing the building typology in high resolution space imagery.

The authors also suggested a damage scale for describing the damage state level suffered by buildings due to tsunami forces: " $D 0=$ No damage", " $D 1=$ Light damage", " $D 2=$ Moderate damage", " $D 3=$ Important damage", " $D 4=$ Heavy damage", and " $D 5=$ Collapse". They finally derived damage functions for the buildings of class " $\mathrm{B}$ " (brick not-reinforced individual building), where the mean damage level is linked to the tsunami flow depth. Only the buildings within a buffer zone of $100 \mathrm{~m}$ around a water mark measurement were chosen to build this damage function (161 units).

\subsection{Expansion of the database}

In order to develop new damage functions for other building typologies, it was necessary to extend the available database. In fact, 4095 buildings of the initial database could not be classified according to their vulnerability during the field survey, due to the fact that all of these buildings collapsed (damage level " $D 5$ ", total destruction). It was crucial to try to assign a vulnerability class also to these buildings because, if they had not been taken into account, the damage functions would have been mistaken and the expected damage level strongly underestimated.

In order to test the accuracy when extracting the building's typology by earth observation, an exercise of photointerpretation was performed on Quick Bird images (spatial resolution up to $60 \mathrm{~cm}$ ) dating from June 2004. Three different observers with different backgrounds took part in this exercise. We noticed that some errors could be introduced in the process of assigning a typology class (Guillande et al., 2009). Observers stated that in some cases, it was difficult to differentiate between typology classes " $\mathrm{B}$ " and "C" or classes "A" and "B". A general remark was that a spatial resolution of $1 \mathrm{~m}$ is not enough to extract with accuracy some detailed features such as roof covering material, roof slope, boundary properties, or number of storeys, which can help in recognizing the type of building. It is necessary to use very high resolution imagery with a spatial resolution of 40$60 \mathrm{~cm}$ or better. Moreover, the background and knowledge of the observer is also important when retrieving information by earth observation. A qualified operator who has seen the characteristics of the different types of buildings on the field can be more objective and more efficient in the process of photo-interpretation.

Despite the risk of introducing some errors, a typology was assigned to buildings which were not identified during the field survey of January 2006. Caution was applied during this process, so in cases of doubt, no class was attributed to the building. With this process a total of 2576 buildings could be identified by photo-interpretation. Figure 1 shows the extended data base produced and the distribution of buildings according to their type: "A = light constructions on wood or timber without any design ", " $\mathrm{B}=$ Brick not reinforced masonry", "C = Brick with reinforced column and masonry filling ", " $\mathrm{D}=$ collective buildings, concrete not reinforced ", "E = well designed buildings, made of reinforced concrete with columns and infill walls ", and " $\mathrm{M}=$ religious building - Mosque ”.

\section{Tsunami hydrodynamic loads and building damage}

\subsection{Flow-depth hazard parameter}

Post-disaster measurements of water marks in Banda Aceh were made available by three teams: the French and Indonesian team of the TSUNARISQUE program (Lavigne et al., 2006, 2009), the International Tsunami Survey Team (Borrero, 2005), and a Japanese team (Tsuji et al., 2005). These field surveys were carried out in January 2005.

Since the three teams did not refer to the same reference level and did not apply the same tide corrections, it was necessary to implement some modifications to make the datasets comparable. Before going ahead, it is important to highlight that the expression "flow depth" represents the height of the tsunami wave measured from the ground level up to the water mark observed in field, whereas "water elevation" is defined as the height of the tsunami wave measured from the sea level up to the water mark observed in field.

Frequently, teams have measured the "water elevation" from the sea level on the day of the measure. A correction for the tide was applied to bring the measure to sea level at the time of the earthquake or to mean sea level. Often, the measurements are also converted into values of flow depth. The Borrero team has directly measured the flow depth. Moreover, the terminology used by each team 


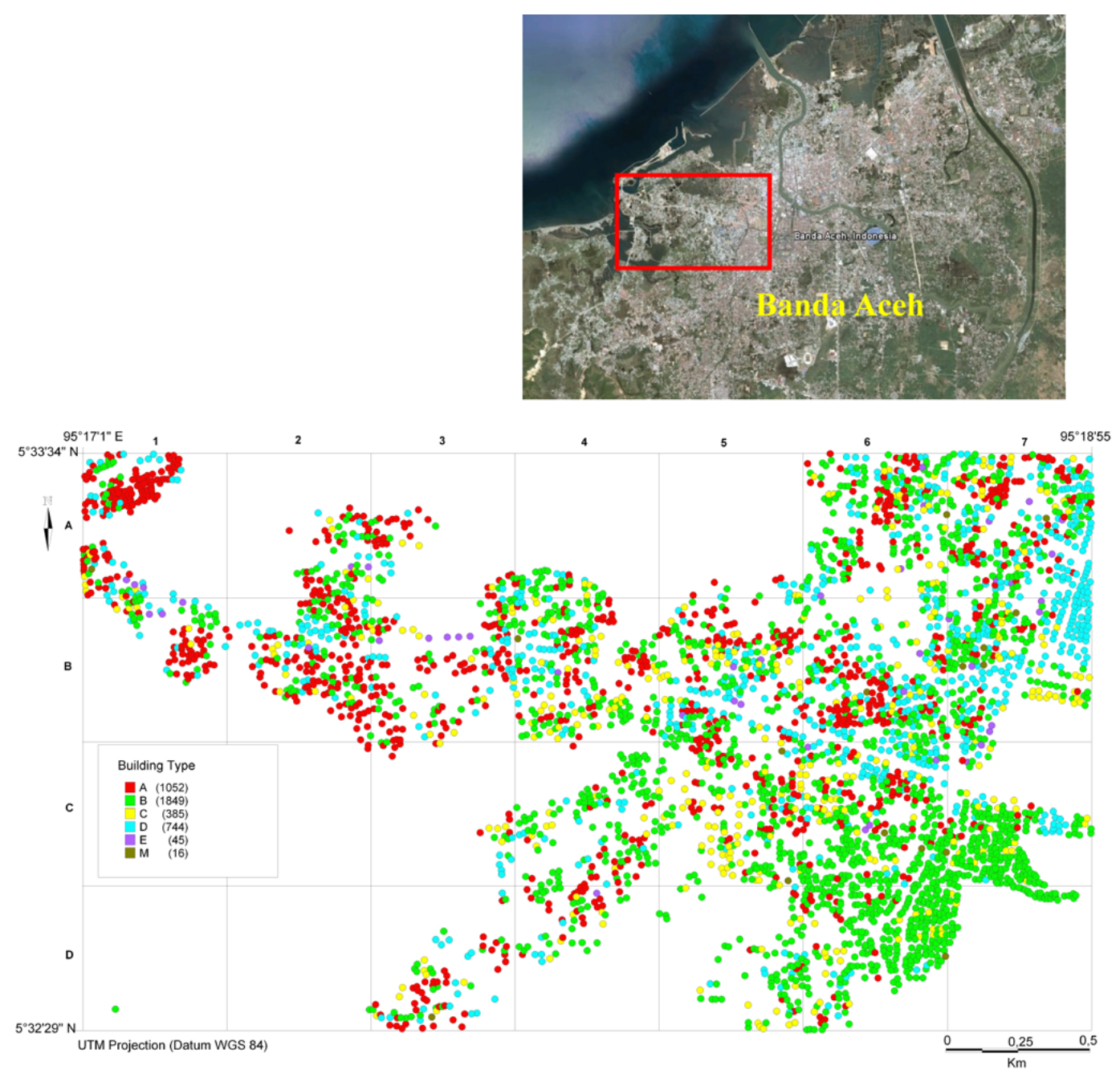

Fig. 1. Map showing the extended database of buildings in Banda Aceh, Indonesia, classified according to their vulnerability ("A" being the most vulnerable, made of wood, single storey, and "E" the most resistant, well designed, made of reinforced concrete with columns and infill walls. "M" stand for Mosque). The total number of buildings per type is given into brackets.

describing the measured parameter ("maximum water level", "tsunami heights", "flow depth") can be misleading.

Once all the measures were brought to the same reference level and converted into "flow depths" (Gardi et al., 2011), they were plotted on a map of the study area for direct comparison (Fig. 2). We noticed important differences between the measurements made by the three teams: values from Lavigne et al. $(2006,2009)$ are very high, while data by Borrero (2005) and Tsuji et al. (2005) seem to be much lower (see Fig. 2). As emphasized by Gardi et al. (2011), these discrepancies could mainly be due to the fact that the TSUNARISQUE team measured the highest water marks visible, while the Tsuji team at numerous points observed and measured several water marks. Different water marks on the same building can correspond to the arrival of several waves, or measures relative to the receding of the sea or differences between the impact of the wave at the front and at the rear of the same building. In these cases, we have retained only the greater value given by the Tsuji team for each of their measurement points.

Once the database of flow depths was established, we computed an interpolation of all field measures, also taking into account the inundation limits observed in Banda Aceh by JICA (Japan International Cooperation Agency, 2005) and TSUNARISQUE program (Lavigne et al., 2006).

In order to obtain the best interpolation for the study, a sensitivity analysis was firstly performed with three different interpolation methods: Ordinary Kriging (Cressie, 1991; Krige, 1996; Baillargeon, 2005), Radial Basis function (Cressie, 1991 Davis, 2002), and Nearest Natural Neighbour (Cressie, 1991; Davis, 2002). Since our interpolation is based on quite few data, the ordinary Kriging is employed with a linear variogram (Cressie, 1991). Initially, a spatial resolution of $80 \mathrm{~m}$ was chosen but the accuracy of the results was not satisfactory. Finally, a spatial resolution of $15 \mathrm{~m}$ was used for each interpolation. This resolution allowed us to 


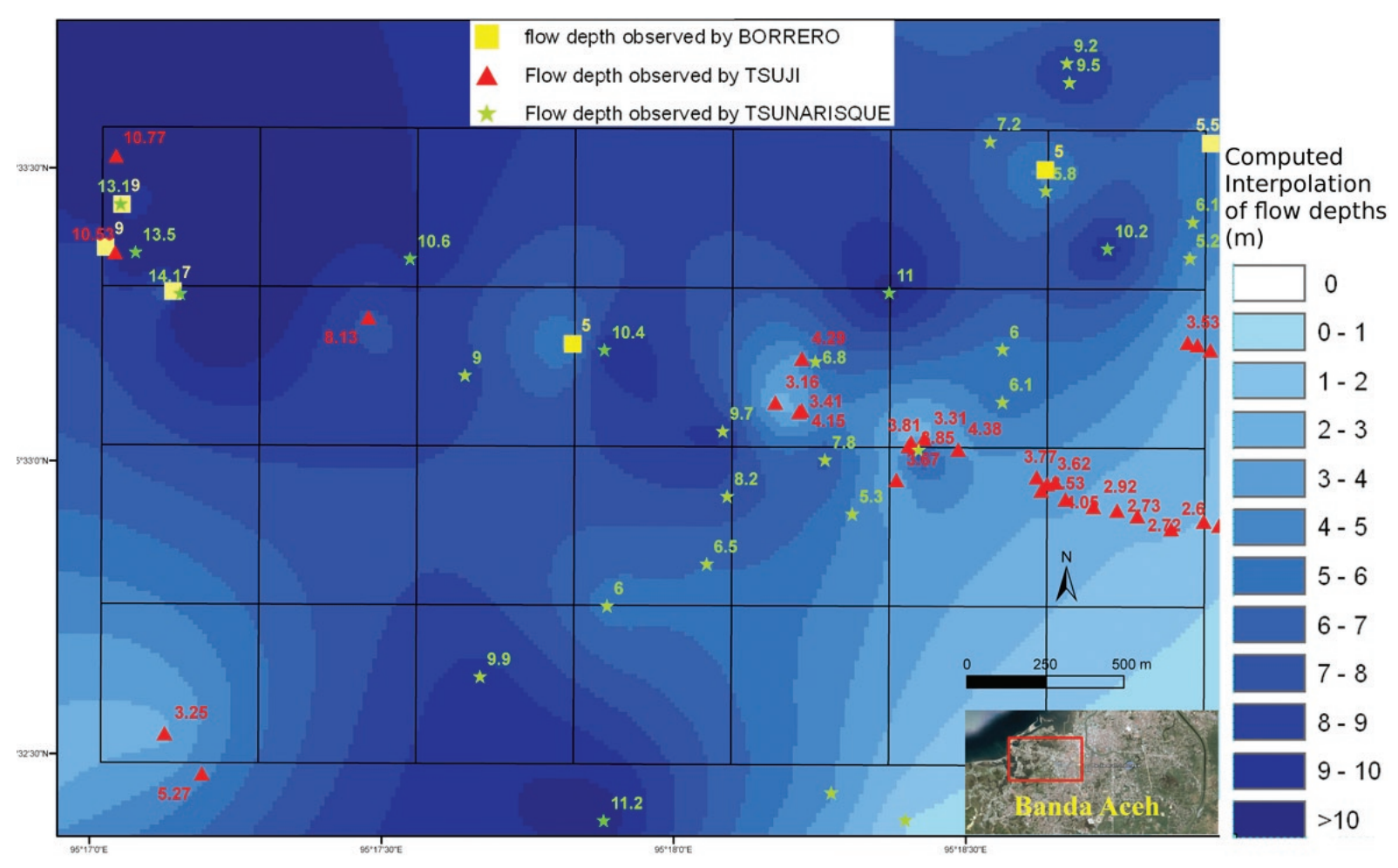

Fig. 2. Computed flow-depth interpolation using Kriging method (grid size $15 \mathrm{~m}$ ) and field measures available for Banda Aceh area (Indonesia) by three teams. The flow-depth parameter represents the height of the tsunami wave measured from the ground level up to the water mark observed in field.

obtain a more accurate interpolation of observed flow depths and to estimate tsunami heights with the available Digital Terrain Model of Banda Aceh (grid size of $18 \mathrm{~m}$ ) created in the framework of the TSUNARISQUE program (Lavigne et al., 2009) and modified by CEA (Commissariat à l'Energie Atomique; Loevenbruck et al., 2007).

In order to compare the spatial accuracy of each interpolation, the minimum Root Mean Square Error (RMSE) was computed with each observed flow depth introduced for the interpolation. The RMSE obtained with the ordinary Kriging was $40 \mathrm{~cm}$, while the RMSE obtained with Natural Neighbour was $1.30 \mathrm{~m}$.

Figure 3 shows the comparison between Natural Neighbour interpolation for a grid size of $80 \mathrm{~m}$ and Kriging interpolation for a grid size of $15 \mathrm{~m}$ against the observed flow depths. We can see that flow depths interpolated with Natural Neighbour method are more scattered from field observations, while flow depths computed with Kriging method seem to be in good concordance with observed flow depths. The interpolation computed with ordinary Kriging method is the most accurate and was chosen for the development of the damage functions.

Finally, by means of a GIS treatment in Vertical Mapper, we allocated a flow depth value to each building of the database.

\subsection{Derivation of fragility curves}

The fragility of a structure is determined with respect to the "capacity" and the limit state function of the structure " $E$ " is provided by the expression:

$E=(R(h)-P(h))$

where $R$ is the capacity of the structure to support a hydrodynamic pressure, and $P$ is the tsunami hydrodynamic pressure acting on the structure. Notice that the variables $R$ and $P$ are functions of the flow depth " $h$ ".

$E$ is the limit state function of the structure that gives the threshold beyond which the structure will suffer some damage $(E<0$ : damage, $E>0$ : security, $E=0$ : limit state). Damage probability is defined as (Lemaire, 2005):

$P_{D}=P[E \leq 0]=P[(R(h)-P(h)) \leq 0]$

The capacity of the structure is generally supposed to be Lognormally distributed (Reed et al., 1994). The conditional probability to have or exceed a given damage " $D$ ” for a given tsunami flow depth " $h$ " is expressed by the function:

$P[D / h]=\Phi\left(\frac{\ln \left(h-\bar{h}_{D}\right)}{\alpha_{D}}\right)$

where: $\Phi(\cdot)$ is the standard normal cumulative distribution function, $\bar{h}_{D}$ is the median value of the flow depth for each 

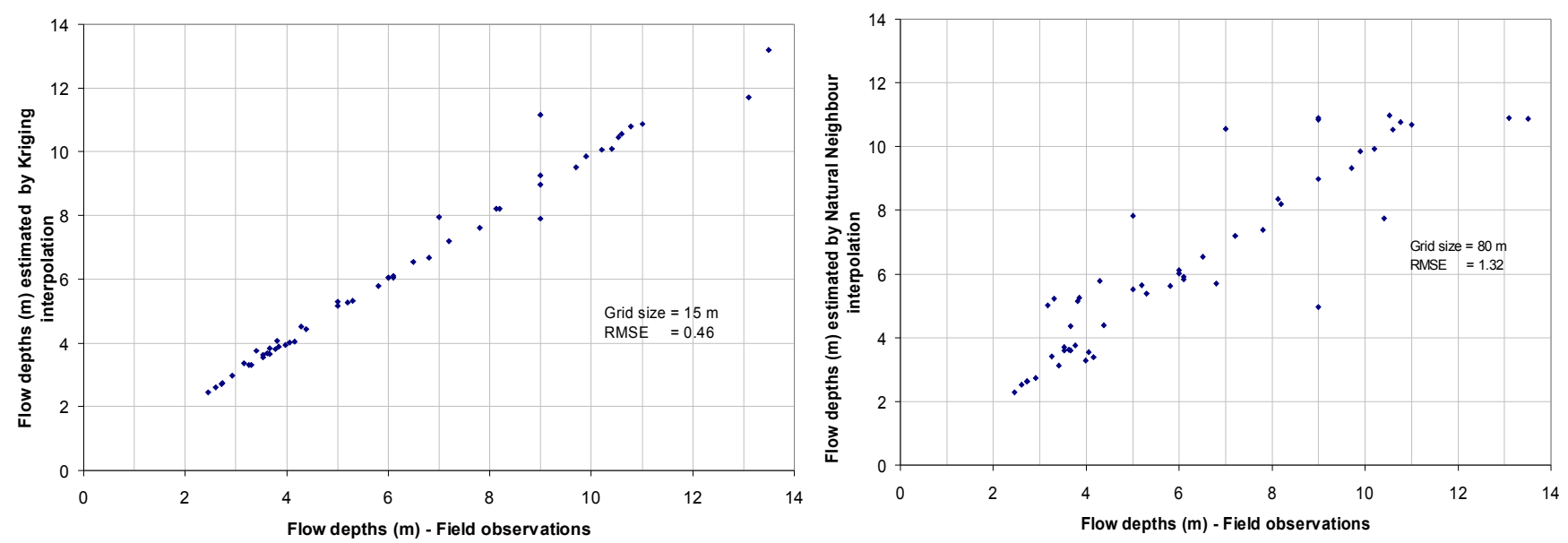

Fig. 3. Comparison between flow depths estimated by Kriging interpolation (grid size $15 \mathrm{~m}$ ) and Natural Neighbour interpolation (grid size $80 \mathrm{~m}$ ) vs observed flow depths by three teams. The RMSE obtained with the ordinary Kriging was $40 \mathrm{~cm}$ while the RMSE obtained with Natural Neighbour was $1.30 \mathrm{~m}$

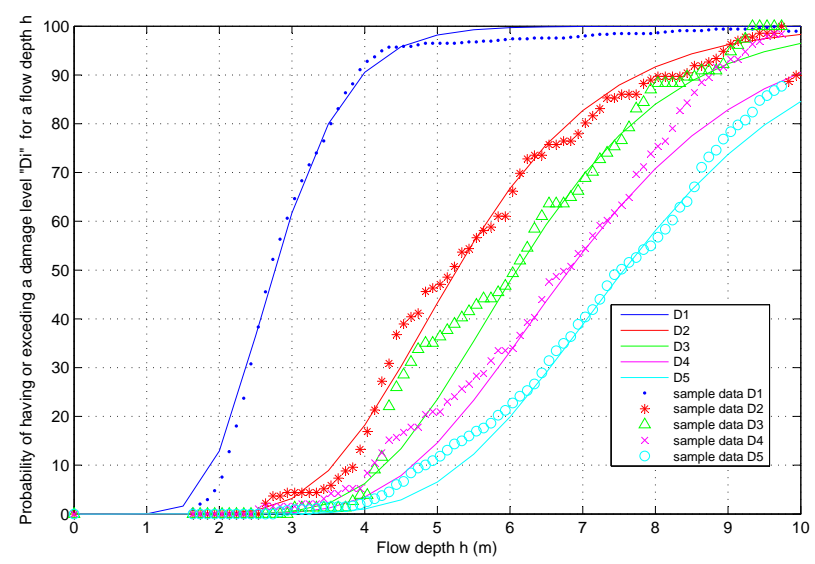

Fig. 4. Fragility curves developed for building typology "B". $D 1$ to $D 5$ denotes the increasing damage level, from light damages to total collapse. Each point of the discrete set corresponds to the empirical cumulative frequency to have damage " $D$ " in the flow-depth interval " $i$ ".

damage state " $D$ "; $h$ is the value of the flow depth, and $\alpha_{D}$ is the standard deviation of the natural logarithm of " $h$ " for each damage state " $D$ " that can be obtained by Eqs. (4) and (5). So, fragility curves are defined by two parameters $\bar{h}_{D}$ and $\alpha_{D}$, where:

$\alpha_{D}^{2}=\sum_{i=1}^{k} \frac{n_{i} \times \overline{h_{D}^{2}}}{N}-\mu_{H}^{2}$

$\mu_{H}=\sum_{i=1}^{k} \frac{n_{i} \times \ln \left(\bar{h}_{D}\right)}{N}$

For each damage state " $D$ ", we have obtained a cumulative histogram of damage as a function of the flow depth
Table 1. Values for the obtained parameters $\bar{h}_{D}$ and $\alpha_{D}$ for the fragility functions we derived. $R^{2}$ is the linear regression coefficient determined through the least-squares fitting for each fragility curve.

\begin{tabular}{llll}
\hline $\begin{array}{l}\text { Damage } \\
\text { state level }\end{array}$ & $\bar{h}_{D}$ & $\alpha_{D}$ & $R^{2}$ \\
\hline$D 1$ & 2.76 & 0.28 & 0.9981 \\
$D 2$ & 5.26 & 0.30 & 0.9978 \\
$D 3$ & 6.09 & 0.27 & 0.9941 \\
$D 4$ & 6.81 & 0.29 & 0.9966 \\
$D 5$ & 7.57 & 0.28 & 0.9978 \\
\hline
\end{tabular}

" $h$ ". In Fig. 4 we can see that each point of the discrete set corresponds to the empirical cumulative frequency to have damage " $D$ " in the flow-depth interval " $i$ ", with step of $0.1 \mathrm{~m}$. The frequency to have damage " $D$ " is defined as $f_{i}=\frac{n_{i}}{N}$. where $n_{i}=$ total number of buildings with damage state " $D j$ " in the flow-depth interval " $i$ "; $N=$ total number of buildings with damage state " $D j " ; j=1$ to 5 . A statistical analysis was undertaken in order to obtain fragilities curves for building typology "B".

Table 1 shows the values obtained for the parameters $\bar{h}_{D}$ and $\alpha_{D}$ for the fragility functions we derived. $R^{2}$ is the linear regression coefficient determined through the least-squares fitting for each fragility curve. Derived fragility curves are shown in Fig. 4. Fragility curves give, for each flow depth value, the probability of incurring damage $\geq D 1$ and the probability of incurring damage $\geq D 2$, etc. up to the probability of incurring total destruction (D5). However, when producing damage maps for different scenarios of tsunami, these kind of functions are not suitable because it becomes very complicated to manage all the information associated 


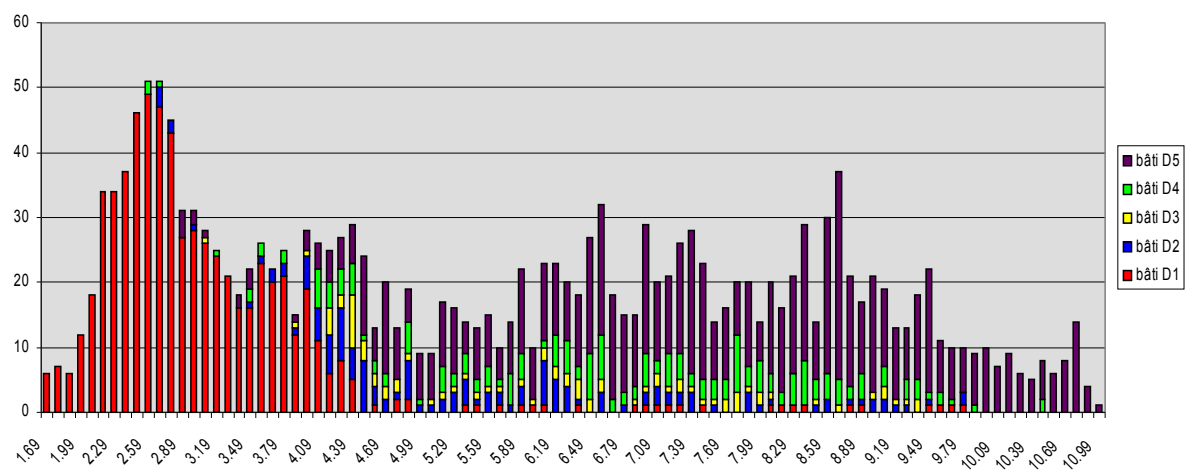

Fig. 5. Histogram showing the distribution data for building vulnerability class "B". Each colour represents a damage state " $D j$ ", $j=1$ to 5 . (" $D 0=$ No damage", " $D 1=$ Light damage", " $D 2=$ Moderate damage", " $D 3=$ Important damage", " $D 4=$ Heavy damage", " $D 5=$ Collapse").

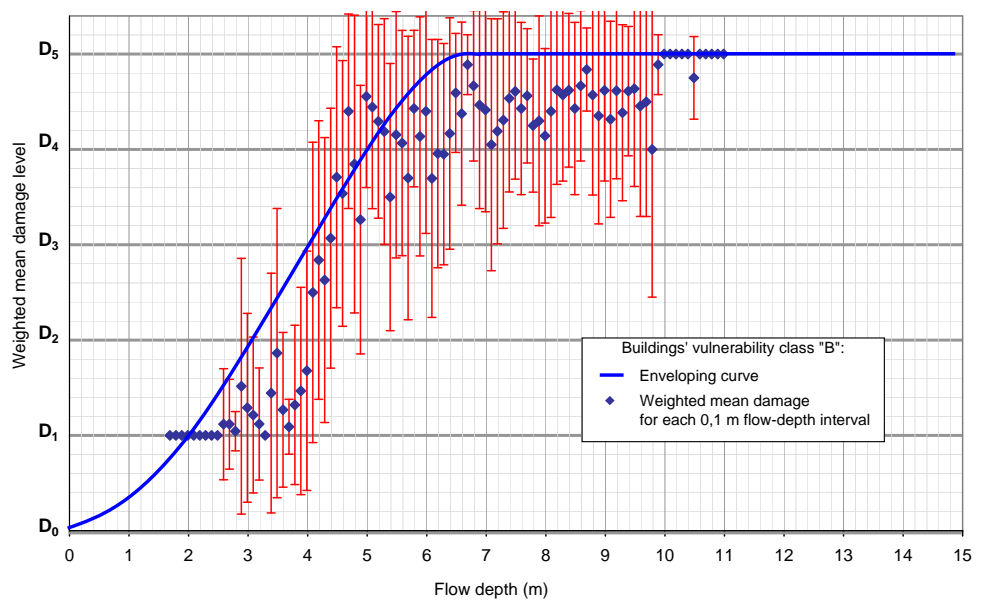

Fig. 6. Enveloping curve of the weighted mean damage level for building vulnerability class "B". Standard deviation for mean damage level $\bar{D}_{i}$ is shown with red bars.

with one level of flow depth, knowing that a tsunami hazard scenario is composed by a spatial distribution of flow depths. For this reason, it was decided to use a simplified methodology to link the flow depth to one damage level, thus obtaining a set of damage functions. The procedure adopted is described hereafter.

\subsection{Derivation of damage curves}

For every typology class ("A", "B", "C" and "D"), a set of intervals of flow depth was generated with step of $0.1 \mathrm{~m}$ from the minimum value " $h_{\min }$ " to the maximum value " $h_{\max }$ ". Then, for each flow-depth interval, the number of buildings presenting a certain damage level (" $D 1$ ", " $D 2$ ", “ $D 3$ ”, “ $D 4$ " or " $D 5$ ") was calculated. As a consequence, the number of buildings in each interval of flow depth is different, as shown in the histogram of data for building typology " $\mathrm{B}$ " (Fig. 5). For this reason we have computed the "weighted" mean damage level for each flow-depth interval. Notice in Eq. (6) that "the weight" corresponds to the total number of buildings with damage state " $D j$ " for the flow-depth interval " $i$ ". The values from 1 to 5 in Eq. (6) represent the damage scale adopted (from " $D 0=$ No damage" to " $D 5=$ Collapse"). Based on the works by Ruangrassamee et al. (2006) and Leone et al. (2010), the weighted mean of damage level " $\bar{D}_{i}$ " was computed with Eq. (6):

$\bar{D}_{i}=\frac{1 \times n D 1_{i}+2 \times n D 2_{i}+3 \times n D 3_{i}+4 \times n D 4_{i}+5 \times n D 5_{i}}{n D 1_{i}+n D 2_{i}+n D 3_{i}+n D 4_{i}+n D 5_{i}}$

where: $n D 1_{i}=$ total number of buildings with Damage " $D 1$ " for the flow-depth interval " $i$ " ; $n D 2_{i}=$ total number of buildings with Damage " $D 2$ " for the flow-depth interval " $i$ "; etc.

The standard deviation " $\sigma_{D i}$ " was calculated for each flow-depth interval using Eq. (7). 
$\sigma_{D i}^{2}=\frac{n D 1_{i} \times\left(1-\bar{D}_{i}\right)^{2}+n D 2_{i} \times\left(2-\bar{D}_{i}\right)^{2}+n D 3_{i} \times\left(3-\bar{D}_{i}\right)^{2}+n D 4_{i} \times\left(4-\bar{D}_{i}\right)^{2}+n D 5_{i} \times\left(5-\bar{D}_{i}\right)^{2}}{n D 1_{i}+n D 2_{i}+n D 3_{i}+n D 4_{i}+n D 5_{i}}$

As can be seen in Figs. 6 to 9, the standard deviation is represented as an error bar around the weighted damage level $D$.

It was therefore decided to build an enveloping curve based on the extreme values of the weighted mean damage (Fig. 6 to 9). This is in agreement with the SCHEMA project philosophy of adopting a conservative approach to avoid underestimation of the damage level. Several automatic tools exist and have been tested for the construction of an enveloping curve. Since these methods appeared extremely sensitive to the scattering of few isolated data (which could likely be due to some errors or uncertainties), it was finally decided to draw this curve manually.

We can observe in Figs. 6 to 9 that standard deviation of data can be significant. In fact, errors could come from different stages of the process. The standard deviation depends on the number of buildings associated to each flow-depth interval and to each damage level. Besides, errors can be introduced either in the process of determining a damage level during the field survey or when trying to recognize a building typology either in the field or by photo-interpretation.

It is important to remark that these functions do not only represent the damage due to hydrodynamic forces of the tsunami, but damage incurred by buildings as a result from cumulated effects of multiple factors whose damaging impact can not be independently assessed:

- Effects due to the impact of debris and floating objects;

- effect of the earthquake in the region of Banda Aceh that has generated the tsunami;

- effects of other factors such as scouring, erosion, etc.

Figures 6 to 9 present the damage functions produced for each building class. We can see a link between the evolution of the damage level as a function of the flow depth and the intrinsic characteristics of resistance of the various buildings.

\subsubsection{Class A}

Considering the class " $\mathrm{A}$ " (1052 units) that represents the light constructions, we can observe, in Fig. 7, that data are very scattered between flow depths 0 to $3 \mathrm{~m}$. Starting from a flow depth of $3 \mathrm{~m}$, a big stock of buildings reaches the highest damage level " $D 5$ " (total collapse), which confirms the high fragility of class "A". We noticed that the standard deviation is equal to zero for all the data in the last part of the curve.

\subsubsection{Class B}

The class " $\mathrm{B}$ " vulnerability curve, already introduced, is based on a large and representative sample of 1849 units. This class represents the masonry constructions that are more resistant than the constructions of the class "A". In Fig. 6, we observed a uniform evolution in the damage level. The enveloping curve of typology class " $\mathrm{B}$ " was elaborated based on this trend. We can observe that the standard deviation for the mean damage level $\bar{D}_{i}$ plotted in this figure fits an upper limit and a lower limit for this curve (see Fig. 6).

\subsubsection{Class $\mathrm{C}$}

This vulnerability class (385 units) corresponds to the masonry constructions with reinforced columns. It is more resistant than the class "A" and class "B". For example, with a flow depth of $3 \mathrm{~m}$, total destruction " $D 5$ " is incurred for building class " $\mathrm{A}$ " (Fig. 7), while the damage level for the class " $C$ " is expected between " $D 1$ " and " $D 2$ " (see Fig. 8). Class " $\mathrm{C}$ " buildings are expected to suffer total destruction (damage level " $D 5$ ”) for flow depths greater than $7 \mathrm{~m}$.

\subsubsection{Class D}

The constructions of the class " $D$ " correspond to nonengineered concrete buildings. A stock of 744 units was available. From Fig. 9, we noticed that for values of flow depth between 0 and $3 \mathrm{~m}$, the damage level expected is between " $D 1$ " and " $D 3$ "; while for flow depth greater than $4 \mathrm{~m}$, data are gathered between damage levels " $D 4$ " and " $D 5$ ". This kind of building seems to be more vulnerable than those of class "B". This behaviour could seem surprising but, as explained by Saatcioglu et al. (2006), the lower capacity resistance of non-engineered reinforced concrete buildings can be explained by the performance of the columns, which are especially vulnerable to lateral tsunami pressures and to the impact forces generated by floating debris.

\subsubsection{Class $\mathrm{E}$}

Considering the low sample of buildings available for class "E" (45 units), it was not possible to develop a damage function for this class.

\subsection{Adaptation to European context}

After the Indonesian tsunami of 2004, various authors (Peiris, 2006; Garcin et al., 2007; Leone et al., 2010) have 


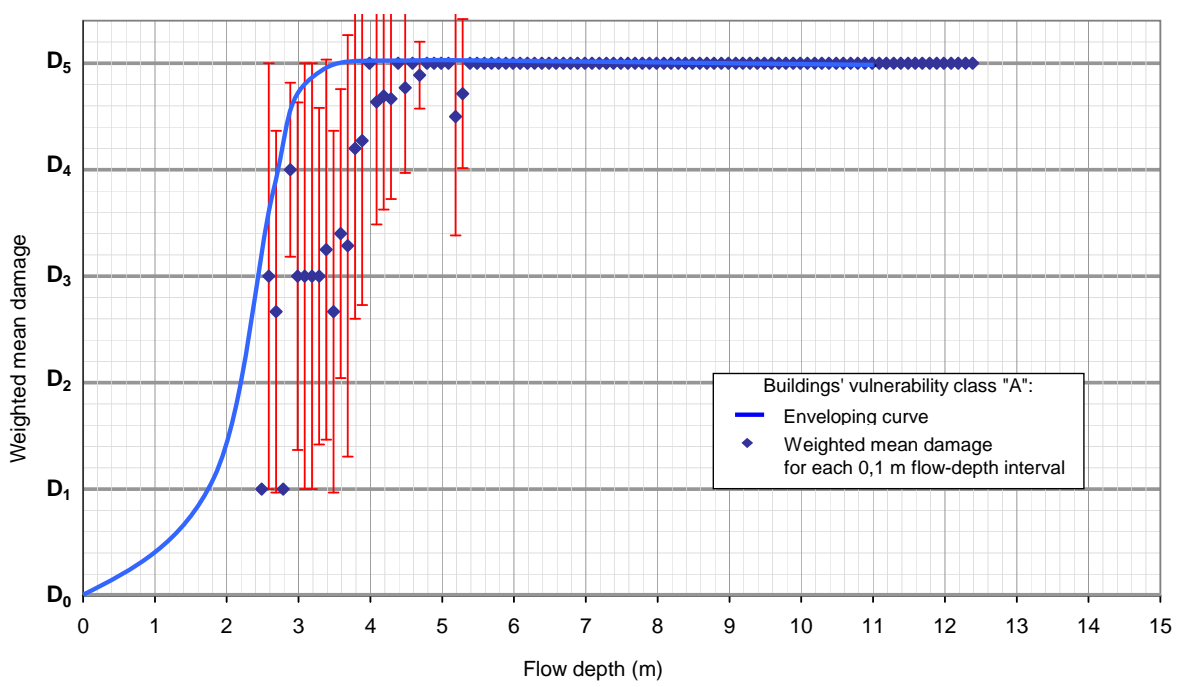

Fig. 7. Enveloping curve for the building vulnerability class "A". Standard deviation for mean damage level $\bar{D}_{i}$ is shown with red bars.

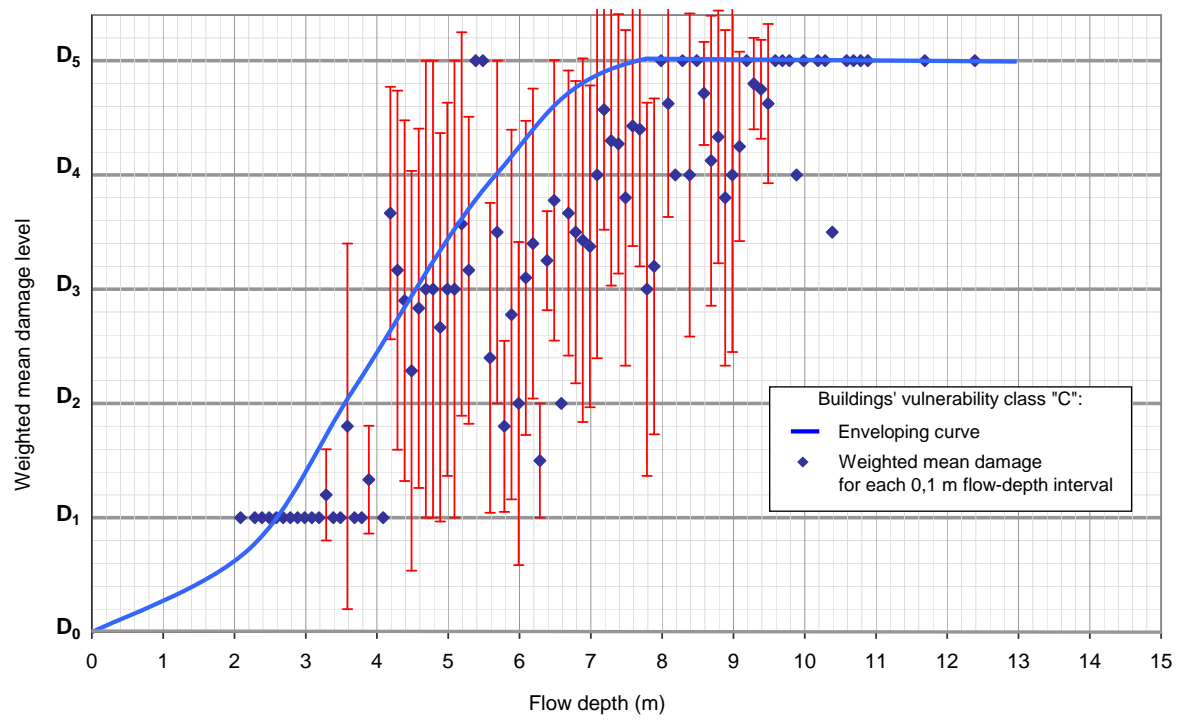

Fig. 8. Enveloping curve for building vulnerability class "C". Standard deviation for mean damage level $\bar{D}_{i}$ is shown with red bars.

proposed typologies of buildings based on field observations collected in the areas affected by the Boxing Day tsunami.

In the framework of the SCHEMA project, a recognition process was done in order to identify in the five test sites of the project (Setubal, Portugal; Mandelieu, France; Catania, Italy; Balchik, Bulgaria; Rabat, Morocco) those buildings which present similarities (in structure, construction material, number of storeys) with the building typologies identified in Indonesia.

The classification has also been completed and enlarged in order to include the type of constructions present at the five test sites of SCHEMA (SCHEMA Consortium, 2009a). New building classes were identified (i.e. historical build- ings, hangars, clay constructions, lava-stone constructions). However, we did not have available data to develop damage functions for these new typologies. The classes for which damage functions have been developed are resumed in Fig. 10, together with field and aerial views of these types of buildings for the French test site.

Since until now there is no building code applied in Europe concerning the tsunami resistance for structures and no sufficient post-tsunami observations exist in the Mediterranean coasts, we assume that at a first order the buildings of types A, B, C, and D in European-Mediterranean regions would react in a similar way as did the equivalent buildings in Indonesia. 


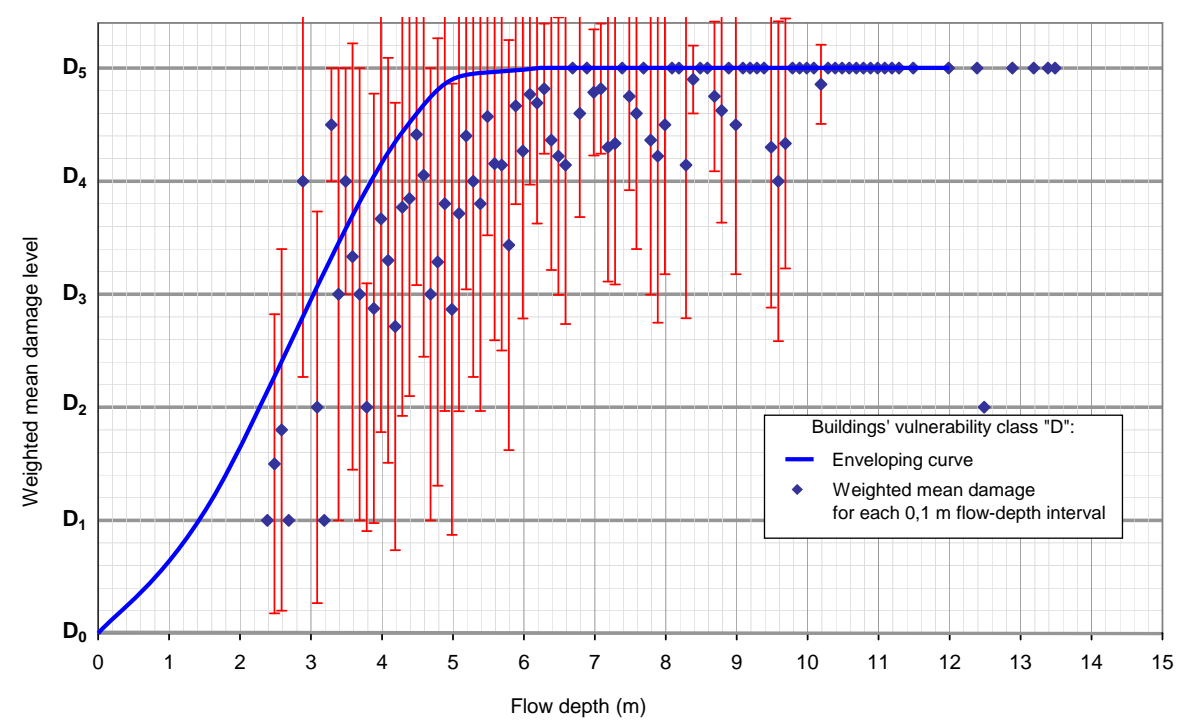

Fig. 9. Enveloping curve for building vulnerability class "D". Standard deviation for mean damage level $\bar{D}_{i}$ is shown with red bars.

\subsection{GIS Interface for production of maps of expected damages}

In order to produce damage maps, the damage functions presented in Sect. 4.3 have been converted into thresholds in order to obtain a damage matrix readable in a GIS.

For the production of maps, a software package (DamASCHE) has been developed as a module for ArcGIS, able to handle geo-referenced data in a raster format (SCHEMA Consortium, 2009b). Three types of input are required by this module:

- a raster layer representing the hazard parameter;

- a shapefile layer of points representing the building locations, with a file containing information on their vulnerability class (“A”, "B", "C", or "D”);

- the damage matrix.

The DamASCHE tool overlays the different data layers and gives the estimated level of damage expected for each building as a function of its building class and flow depth foreseen in its location. Finally, the user can display the damage scenario map, showing the distribution of buildings, each one represented with a colour showing the expected damage to it.

\section{Conclusions}

In the framework of the SCHEMA project, new tsunami damage functions were developed for different typologies of buildings. The available building database derived from Leone et al. (2010) has been extended and completed. A building typology, depending on the type of construction material, was assigned by photo-interpretation to those buildings not identified during the field survey carried out in Indonesia just after the December 2004 tsunami.

Additionally, the post-disaster observations of water levels published by three different teams have been analysed and gathered with the purpose of creating an increased database for the flow depth hazard parameter, to which the damage level on buildings is linked.

An interpolation with all flow depth observations was therefore computed in order to obtain the spatial distribution of the tsunami flow depth in Banda Aceh. The obtained results seem to be consistent with the field measures.

Several methodologies were studied in order to develop damage functions. We derived fragility functions for building class "B". The cumulative Lognormal distribution function is well fitted to the data. However, when mapping damages for different scenarios of tsunami, these kind of functions are not appropriate.

Therefore, we chose to follow a simplified approach, creating enveloping curves based on the weighted mean damage level: in that way, damage functions were derived for several building classes ("A", "B", "C", and " $D$ "). This is a conservative method in agreement with the worst-case scenario approach followed within the SCHEMA project.

These functions do not only represent the damage due to hydrodynamic forces of the tsunami, but they result from cumulated effects of multiple factors for which it is impossible to separate the respective damaging effect on a building: effects due to the impact of debris and floating objects; effects of the earthquake in the region of Banda Aceh that generated the tsunami; and effects of others factors such as scouring, erosion, etc.

In the framework of the SCHEMA project, the existing classification of buildings (based on their intrinsic resistance) has been adapted to the European context. Similarities have 


\begin{tabular}{|c|c|c|c|c|}
\hline & $\begin{array}{l}\text { Field recognition } \\
\text { criteria }\end{array}$ & Field view & Aerial view & Recognition criteria by EO \\
\hline $\mathbf{A}$ & $\begin{array}{l}\text { Beach or sea front light } \\
\text { constructions: } \\
\text { Wooden, timber, clay } \\
\text { materials, or zinc slabs. }\end{array}$ & & & $\begin{array}{c}\text { Flat roof, steel sheets Small to very } \\
\text { small surfaces. Extended surfaces in } \\
\text { case of beach activities (restaurants, } \\
\text { bars) }\end{array}$ \\
\hline B & $\begin{array}{l}\text { Brick not reinforced } \\
\text { Cement mortar wall, } \\
\text { Fieldstone, Masonry. One } \\
\text { storey. }\end{array}$ & & & $\begin{array}{c}\text { Simple geometry (square, rectangle). } \\
\text { Flat or slope roofs, tile roofs. Little } \\
\text { extension or surface. Located in the } \\
\text { old town. }\end{array}$ \\
\hline $\mathbf{C}$ & $\begin{array}{l}\text { Individual buildings, villas: } \\
\text { Brick with reinforced } \\
\text { column \& masonry filling. } \\
\text { One or two storeys. }\end{array}$ & & & $\begin{array}{l}\text { More complex geometry. Several } \\
\text { levels of roof and several annex. } \\
\text { Pitched roof. Medium to big } \\
\text { dimensions. }\end{array}$ \\
\hline $\mathbf{D}$ & $\begin{array}{l}\text { Non-ingeneered reinforced } \\
\text { concrete buildings. } \\
\text { Collective use. Two to four } \\
\text { floors }\end{array}$ & & & $\begin{array}{l}\text { Tiles roofs. } \\
\text { Located in old town. Elongated } \\
\text { geometry. }\end{array}$ \\
\hline
\end{tabular}

Fig. 10. Building typology depending on the resistance capacity of the constructions for Mandelieu test site (adapted from Leone et al., 2010; Peiris, 2006; Saatciouglu et al., 2006; Ghobarah et al., 2006; Reese et al., 2007). Only the classes for which we developed damage functions are shown here.

been found between the typology of buildings studied in Banda Aceh and the buildings existing in our EuropeanMediterranean coastal test sites. New building classes, typical of the study areas of the project, were also identified (i.e. historical buildings, hangars, clay constructions, lava-stone constructions). However, we do not have available data to develop damage functions for these new typologies.

Finally, for the production of maps of expected damages, a software package (DamASCHE) has been developed as a module for ArcGIS, and damage functions have been converted into thresholds in order to obtain a damage matrix readable in a GIS.

Acknowledgements. This study has been developed thanks to the support of the European Commission in the framework of the SCHEMA project (contract no. SST5-CT-2006-030963). Yannick Thiery is kindly acknowledged by NV and AG for constructive discussions and his contribution to the sensitivity analysis of interpolation methods. This article greatly benefited from comments by S. Reese and three other anonymous referees.

Edited by: S. Monserrat

Reviewed by: S. Reese and three other anonymous referees

\section{References}

Baillargeon, S.: Le krigeage: revue de la théorie et application à l'interpolation spatiale de données de précipitations. Mémoire de Maitrise es Sciences de la Faculté des Etudes Supérieures de l'Université de Laval, 137 pp., 2005.

Borrero, J.: Field survey of northern Sumatra and Banda Aceh, Indonesia after the tsunami and earthquake of 26 December 2004, Seismol. Res. Lett., 76, 309-317, 2005.

Cressie, N. A. C.: Statistics for Spatial Data, John Wiley and Sons, Inc., New York, 900 pp., 1991. 
Dall'Osso, F., Cavalletti, A., and Polo, P.: Risk assessment and evaluation ArcGIS toolbox: User's Manual, available at: http://www.preventionweb.net/files/2945 RISK20ASSESSMENT20AND20EVALUATION20A5forprint. pdf (last access: September 2010), 2006.

Davis, J. C.: Statistics and Data Analysis in Geology, 3rd Edn., John Wiley \& Sons, New York, 638 pp., 2002.

Garcin, M., Prame, B., Attanayake, N., De Silva, U., Desprats, J. F., Fernando, S., Fontaine, M., Idier, D., Lenotre, N., Pedreros, R., and Siriwardana, C. H. E. R.: A Geographic Information System for Coastal Hazards. Application to a pilot site in Sri Lanka (Final Report), BRGM Open file BRGM/RP-55553-FR, 124 pp., 2007.

Gardi, A., Valencia, N., Guillande, R., and André, C.: Inventory of uncertainties associated with the process of tsunami damage assessment on buildings (SCHEMA FP6 EC co-funded project), Nat. Hazards Earth Syst. Sci., 11, 883-893, doi:10.5194/nhess11-883-2011, 2011.

Guillande, R., Valencia, N., and Gardi, A.: Uncertainties in modeling and damage assessment of tsunami risk, implications for crisis management (FP6 SCHEMA project), Provence 2009 International Conference, Aix-en-Provence, France, 6-8 July, 2009.

Ghobarah, A., Saatcioglu, M., and Nistor, I.: The impact of the 26 December 2004 earthquake and tsunami on structures and infrastructure, Eng. Struct., 28, 312-326, 2006.

Japan International cooperation Agency (JICA): The study on the urgent rehabilitation and reconstruction support program for Aceh province and affected areas in north Sumatra, JICA, japan, Final Report (1), Vol. IV, 2005.

Krige, D. G.: Two dimensional weighted moving average trend surfaces for ore-evaluation, J. S. Afr. I. Min. Metall., 66, 13-38, 1966.

Koshimura, S.: Tsunami vulnerability assessment for the city of Banda Aceh using the tsunami numerical model and the posttsunami survey data, IUGG XXIV General Assembly, Perugia, Italy, 2-3 July 2007, JSS002 Symposium, oral presentation 1767, 2007.

Koshimura, S., Oie, T., Yanagisawa, H., and Imamura, F.: Developing fragility functions for tsunami damage estimation using numerical model and post-tsunami data from Banda Aceh, Indonesia, Coast. Eng. J., Jpn. Soc. Civil Eng., 51, 243-273, 2009a.

Koshimura, S., Namegaya, Y., and Yanagisawa, H.: Tsunami Fragility : A new measure to assess tsunami damage, J. Disaster Res., 4, 479-488, 2009b.

Lavigne, F., Paris, R., Grancher, D., Wassmer, P., Setiawan, A., Syahnan, Gunawan, T., Fachrizal, Waluyo, Cahyadi, R., Flohic, F., De Coster, B., and Mahieu, L.: Le tsunami du 26 décembre 2004: chronologie et reconstitution de la catastrophe dans la région de Banda Aceh (Sumatra, Indonésie), Scientific report of the TSUNARISQUE programme (2005-2006), consortium franco-indonésien, France, 2006.

Lavigne, F., Paris, R., Grancher, D., Wassmer, P., Brunstein, D., Vautier, F., Leone, F., Flohic, F., De Coster, B., Gunawan, T., Gomez, Ch., Setiawan, A., Cahyadi, R., and Fachrizal: Reconstruction of tsunami inland propagation on December 26, 2004 in Banda Aceh, Indonesia, through field investigations, Pure Appl. Geophys., 166, 259-281, doi:10.1007/s00024-008-04318, 2009.

Leone, F., Denain, J. C., Vinet, F., and Bachri, S.: Analyse spa- tiale des dommages au bâti de Banda Aceh (Sumatra, Indonésie): contribution à la connaissance du phénomène et à l'élaboration de scénarios de risque tsunami, in: Scientific internal report of TSUNARISQUE programm (2005-2006), Délégation Interministérielle pour l'aide Post-Tsunami (DIPT), consortium francoindonésien, 306 pp., 2006.

Leone, F., Lavigne, F., Paris, R., Denain, J.-C., and Vinet, F.: A spatial analysis of the December 26th, 2004 tsunami-induced damages: Lessons learned for a better risk assessment integrating buildings vulnerability, Appl. Geogr., 31, 363-375, doi:10.1016/j.apgeog.2010.07.009, 2010.

Lemaire, M.: Fiabilité des structures: couplage mécano-fiabiliste statique, Ed. Hermès-Lavoisier, France, 506 pp., 2005.

Loevenbruck, A., Hébert, H., Schindelé, F., Sladen, A., Lavigne, F., Brunstein, D., Wassmer, P., and Paris, R.: Detailed Modeling of the 2004 Tsunami Flooding in the Banda Aceh and Lhok, Nga Districts (Sumatra, Indonesia), Eos Trans. AGU, 88 (52), Fall Meet. Suppl., Abstract 1 S53A-1042, 2007.

Papadopoulos, G. and Dermentzopoulos, T.: A Tsunami Risk Management Pilot Study in Heraklion, Crete, Nat. Hazards, 18, 91118, 1998.

Papathoma, M., Dominey-Howes, D., Zong, Y., and Smith, D.: Assessing tsunami vulnerability, an example from Herakleio, Crete, Nat. Hazards Earth Syst. Sci., 3, 377-389, doi:10.5194/nhess-3377-2003, 2003.

Peiris, N.: Vulnerability functions for tsunami loss estimation, First European conference on Earthquake Engineering and Seismology: a joint event of the 13th ECEE and 30th General Assembly of the ESC, Geneva, Switzerland, Paper number 1121, 2006.

Reed, J. W. and Kennedy, R. P.: Methodology for Developing Seismic Fragilities, EPRI (Electric Power Research Institute), Report TR-103959, 1994.

Reese, S., Cousins, W. J., Power, W. L., Palmer, N. G., Tejakusuma, I. G., and Nugrahadi, S.: Tsunami vulnerability of buildings and people in South Java - field observations after the July 2006 Java tsunami, Nat. Hazards Earth Syst. Sci., 7, 573-589, doi:10.5194/nhess-7-573-2007, 2007.

Ruangrassamee, A., Yanagisawa, H., Foytong, P., Lukkunaprasit, P., Koshimura, S., and Imamura, F.: Investigation of tsunamiinduced damage and fragility of buildings in Thailand after the December 2004 Indian Ocean Tsunami, Earthq. Spectra, Special Issue III, 22, S377-S401, 2006.

Saatcioglu, M., Ghobarah, A., and Nistor, I.: Performance of structures in Thailand during the december 2004 great Sumatra earthquake and Indian ocean tsunami, Earthq. Spectra, Special Issue III, 22, S355-S375, 2006.

SCHEMA Consortium: Generic aspects and rules on vulnerability evaluation, WP2.2.1 Definition of tsunami vulnerability criteria (primary, secondary) and damage, Scientific report n. D2.1 of the SCHEMA Project, 87 pp., 2009a.

SCHEMA Consortium: The common methodology, Scientific report no. D2.2 of the SCHEMA Project, 43 pp., $2009 \mathrm{~b}$.

Tsuji, Y., Matsutomi, H., Tanioka, Y., Nishimura, Y., Sakakiyama, T., Kamataki, T., Murakami, Y., Moore, A., and Gelfenbanm, G.: Distribution of the Tsunami Heights of the 2004 Sumatera Tsunami in Banda Aceh measured by the Tsunami Survey Team, available at: http://www.eri.u-tokyo.ac.jp/namegaya/ sumatera/surveylog/eindex.htm, last access: September 2010, 2005. 